\title{
Defining and expanding the phenotype of QARS- associated developmental epileptic encephalopathy
}

Katrine M. Johannesen, MD, * Diana Mitter, MD, * Robert Janowski, PhD, Christian Roth, MD, Joseph Toulouse, MD, Anne-Lise Poulat, MD, Dorothee M. Ville, MD, Nicolas Chatron, MD, Eva Brilstra, MD, Karin Geleijns, MD, Alfred Peter Born, MD, Scott McLean, MD, Kimberly Nugent, MS, Gareth Baynam, MD, Cathryn Poulton, PhD, Lauren Dreyer, BCur, Dylan Gration, MD, Solveig Schulz, MD, Andrea Dieckmann, MD, Katherine L. Helbig, MS, Andreas Merkenschlager, MD, Rami Jamra, MD, Anja Finck, MSc,

Elena Gardella, MD, PhD, Helle Hjalgrim, MD, PhD, Ghayda Mirzaa, MD, Francesco Brancati, MD,

Tatjana Bierhals, MD, Jonas Denecke, MD, Maja Hempel, MD, Johannes R. Lemke, MD, Guido Rubboli, MD, Petra Muschke, MD, Renzo Guerrini, MD, Annalisa Vetro, MD, Dierk Niessing, PhD, Gaetan Lesca, MD, and Rikke S. Møller, PhD

Neurol Genet 2019;5:e373. doi:10.1212/NXG.0000000000000373

\section{Abstract \\ Objective}

The study is aimed at widening the clinical and genetic spectrum and at assessing genotypephenotype associations in QARS encephalopathy.

\section{Methods}

Through diagnostic gene panel screening in an epilepsy cohort, and recruiting through GeneMatcher and our international network, we collected 10 patients with biallelic $Q A R S$ variants. In addition, we collected data on 12 patients described in the literature to further delineate the associated phenotype in a total cohort of 22 patients. Computer modeling was used to assess changes on protein folding.

\section{Results}

Biallelic pathogenic variants in QARS cause a triad of progressive microcephaly, moderate to severe developmental delay, and early-onset epilepsy. Microcephaly was present at birth in $65 \%$, and in all patients at follow-up. Moderate (14\%) or severe (73\%) developmental delay was characteristic, with no achievement of sitting (85\%), walking (86\%), or talking (90\%). Additional features included irritability (91\%), hypertonia/spasticity (75\%), hypotonia (83\%), stereotypic movements (75\%), and short stature (56\%). Seventy-nine percent had pharmacoresistant epilepsy with mainly neonatal onset. Characteristic cranial MRI findings include early-onset progressive atrophy of

\author{
Correspondence \\ Dr. Møller \\ rimo@filadelfia.dk
}

\begin{abstract}
*These authors contributed equally to the manuscript.
From the Department of Epilepsy Genetics and Precision Medicine (K.J.M., E.G., G.R., R.S.M.), The Danish Epilepsy Centre Filadelfia, Dianalund, Denmark; Institute for Regional Health Services (K.J.M., E.G., R.S.M.), University of Southern Denmark, Odense; Institute of Human Genetics (D.M., R. Jamra, A.F., J.R.L.), University of Leipzig Medical Center, Germany; Institute of Structural Biology (R. Janowski, D.N.), Helmholtz Zentrum München - German Research Center for Environmental Health, Neuherberg, Germany; Department of Paediatric Radiology (C.R.), University of Leipzig Medical Center, Germany; Department of Epilepsy, Sleep and Pediatric Neurophysiology (J.T.), Lyon University Hospital, France; Neuropediatric Unit (A.-L.P., D.M.V., G.L.), Lyon University Hospital, France; Department of Medical Genetics (N.C., G.L.), Lyon University Hospital, France; GenDev Team (N.C.), CNRS UMR 5292, INSERM U1028, CNRL and University of Lyon, France; Department of Genetics (E.B.), University Medical Center Utrecht, The Netherlands; Department of Child Neurology (K.G.), Brain Center Rudolf Magnus, University Medical Center Utrecht, The Netherlands; Department of Paediatrics (A.P.B.), Copenhagen University Hospital Rigshospitalet, Denmark; Baylor College of Medicine (S.M., K.N.), Children's Hospital of San Antonio; Undiagnosed Diseases Program (G.B., C.P.), Genetic Services of Western Australia, Department of Health, Government of Western Australia, Perth; Western Australian Register of Developmental Anomalies (G.B., D.G.), Australia; Telethon Kids Institute and the School of Paediatrics and Child Health (G.B.), University of Western Australia, Perth; Linear Clinical Research (L.D.), WA, Australia; Center of Human Genetics (S.S), Jena University Hospital, Germany; Department of Neuropediatrics (A.D.), Jena University Hospital, Germany; Division of Neurology (K.L.H.), Children's Hospital of Philadelphia, PA; Division of Neuropediatrics (A.M.), University of Leipzig Medical Center, Germany; Amplexa Genetics (H.H.), Odense, Denmark; Clinic for Children (H.H.), Værløse, Denmark; Center for Integrative Brain Research (G.M.), Seattle Children's Research Institute, WA; Department of Pediatrics (G.M.), University of Washington, Seattle; Medical Genetics Unit (F.B.), Department of Life, Health and Environmental Sciences, University of L'Aquila, Italy; Istituto Dermopatico dell'Immacolata (F.B.), IDI-IRCCS, Rome, Italy; Institute of Human Genetics (T.B., M.H.), University Medical Center Hamburg-Eppendorf, Germany; Childrens Hospital (.D.), University Medical Center Hamburg-Eppendorf, Germany; University of Copenhagen (G.R.), Denmark; Institute for Human Genetics (P.M.), University Hospital Magdeburg, Germany; Children's Hospital A. Meyer (R.G., A.V.), University of Florence, Italy; and Institute of Pharmaceutical Biotechnology (D.N.), Ulm University, Germany.
\end{abstract}

Go to Neurology.org/NG for full disclosures. Funding information is provided the end of the article.

Author contributions are listed at links.Iww.com/NXG/A200.

The Article Processing Charge was funded by the authors.

This is an open access article distributed under the terms of the Creative Commons Attribution-NonCommercial-NoDerivatives License 4.0 (CC BY-NC-ND), which permits downloading and sharing the work provided it is properly cited. The work cannot be changed in any way or used commercially without permission from the journal. 


\section{Glossary}

ABD = anticodon-binding domain; AED = antiepileptic drug; CATD = catalytic domain; $\mathbf{C P 1}=$ connecting peptide $1 ;$ ID = intellectual disability; mRNA = messenger RNA; NTD = N-terminal domain; $\mathbf{t R N A}=$ transfer RNA.

cerebral cortex (89\%) and cerebellum (61\%), enlargement of ventricles (95\%), and age-dependent delayed myelination (88\%). A small subset of patients displayed a less severe phenotype.

\section{Conclusions}

These data revealed first genotype-phenotype associations and may serve for improved interpretation of new $Q A R S$ variants and well-founded genetic counseling.

QARS (OMIM \#615760) encodes a glutaminyl-tRNA synthetase responsible for linking tRNA with amino acids. ${ }^{1}$ This aminoacylation is essential for translation of mRNA to proteins. ${ }^{2}$ Drosophila studies have shown that QARS-encoded synthetase is crucial for termination of fine branching structures at dendrites and axons during early brain development. ${ }^{1}$ qars $^{-/-}$zebrafish have smaller eyes and brains, progressive neural cell death, and exhibit uncoordinated movements. ${ }^{1}$ Humans have 37 genes encoding different aminoacyl-tRNA synthetases. So far, pathogenic variants have been found in more than $22,{ }^{3-9}$ including AARS (encephalopathy, refractory early-onset epilepsy, microcephaly, growth retardation, and peripheral neuropathy $)^{10}$ and VARS (developmental delay, epileptic encephalopathy, and primary or progressive microcephaly). ${ }^{4,5}$

QARS was first connected to disease in $2014^{1}$ in 4 individuals from 2 unrelated families with severe epilepsy of neonatal onset, severe intellectual disability (ID), and progressive microcephaly with cerebral-cerebellar atrophy. They were found to have compound heterozygous variants in QARS. Cellular in vitro studies of the disease-associated variants have shown a loss of function of the glutaminyl-tRNA synthetase, probably due to misfolding and aggregation of the protein. Further reports confirmed both nonsense and missense variants in QARS as pathogenic. ${ }^{2,11-15}$ The phenotype has been generally consistent with progressive microcephaly, cerebral atrophy, severe ID, and drug-resistant epilepsy. However, among the 12 published patients, a small subgroup with homozygous deleterious variants seems to display a milder phenotype. With this study, we aimed to further define the clinical spectrum associated with pathogenic QARS variants and assess first genotype-phenotype associations.

\section{Methods}

New patients were ascertained through diagnostic screening of an epilepsy cohort, using the EPIDASD (Epilepsy, Intellectual disability and Autism Spectrum Disorders) gene panel at Amplexa Genetics A/S (NM_005051.2) and whole-genome sequencing performed as part of the Undiagnosed Diseases ProgramWestern Australia. ${ }^{16}$ Homozygous variants were reported when present in heterozygous form in $<100$ controls and not seen in homozygous form in controls. All findings were confirmed by Sanger sequencing. All variants were detected in heterozygous state in the parents to prove for biallelic variants in the index patients. Further patients were recruited through an international network of clinical geneticists and physicians working with severe epilepsy and GeneMatcher. ${ }^{17}$ Available cranial MRI data sets were reviewed by a single neuroradiologist (C.R.).

Clinical information including data on phenotype, epilepsy, EEG, neuroimaging, and treatment response was evaluated for all the patients included in the article. Seizures and epilepsy syndromes were classified according to the International League Against Epilepsy. ${ }^{18,19}$ A PubMed search using the search term "QARS" was performed to obtain information on all previously published cases. Additional information was added by the referring physicians on 2 previously reported patients. ${ }^{1}$

Variants were assumed pathogenic or likely pathogenic, if they were homozygous or compound heterozygous, nonsynonymous, splice site altering, or frameshift changing. Variants were tested with prediction software (PolyPhen-2, SIFT, and MutationTaster) for probable pathogenicity. The gnomAD database was used to check allele frequency in healthy controls. Variants were classified pathogenic or likely pathogenic according to the recommendations for interpretation of sequence variants published by the American College of Medical Genetics and Genomics. ${ }^{20,21}$

Variants were modeled in silico, based on the crystal structure of the intact human GlnRS at $2.4 \AA$ resolution. ${ }^{22}$ The model was analyzed using the program COOT. ${ }^{23}$ Point mutations were introduced in silico using the standard rotamer library of COOT and analyzed for the appearance of steric clashes or repulsive forces of side chains. Splice site variants gave an unknown protein product and could not be modeled. Figures were prepared using the program Pymol (pymol.org). Upon request, access to data will be given to those eligible for this.

(1) This study was approved by the local ethical authorities of University Hospital Medical Center Leipzig and University Center for Rare Diseases Leipzig. (2) Genetic analysis in the 
patients reported in this study was performed through diagnostic screening. No additional experiments were performed. For retrospective analysis and genotype-phenotype assessment of genetic and clinical data, approval from the ethical standards committee was received. (3) All legal parents (all patients were minors) provided written informed consent for research. (4) Authorization has been obtained for disclosure (consent-to-disclose) of any recognizable persons in photographs or other information in this article. (5) This study is not included in a public trials registry. Data Availability Statement: All relevant clinical and genetic data of the patients in this study are shared and provided in the article, including supplemental material.

\section{Results}

We collected a cohort of 22 patients ( 10 new patients and 12 published patients) from 18 families with recessive pathogenic biallelic variants in QARS. The cohort includes $11 \mathrm{fe}-$ male and 11 male patients; mean age at follow-up was 59 months (range 5 months to $106 / 12$ years). Of note, patient 2 had a brother with a similar phenotype who died before genetic testing could be performed (for details of the brother, see supplemental data appendix e-1, links.lww.com/NXG/ A199). Table 1 provides clinical, radiographic, and epilepsy characteristics of the new patients (for data on all 22 patients, see supplemental data table e-1, links.lww.com/NXG/A195; for epilepsy phenotype, table e-2, links.lww.com/NXG/ A196). Two patients (3 and 21) were children of consanguineous parents, 3 patients from 2 families $(16,17$, and 18) were Ashkenazi Jews. The others were children of unrelated healthy parents.

\section{QARS-associated phenotype in the cohort of 22 patients}

All patients were born after uncomplicated pregnancies. Microcephaly was present at birth in 65\% (11/17 patients) and in all patients with available measurements (19/19 patients) at follow-up (range $-2.1 \mathrm{SD}$ to $-17.2 \mathrm{SD}$ ). Five patients were diagnosed with microcephaly already in utero $(1,2,7,8$, and 22). Regarding overall growth, $21 \%$ (3/14 patients) had short birth length, and $56 \%$ (9/16 patients) had short stature at follow-up (range -2.2 SD to $-5.6 \mathrm{SD}$ ). At follow-up, 13\% (2/ 15) showed dystrophy, and 8 patients were reported with a gastrostomy tube. All patients showed delay of motor and speech development. Seventy-three percent (16/22 patients) had severe developmental delay, and 14\% (3/22 patients) had moderate delay. Eighty-five percent (17/20 patients) showed no achievement of unassisted sitting, $86 \%$ (18/21 patients) no achievement of unassisted walking, and $90 \%$ (18/20 patients) were reported with no speech at follow-up.

Hypotonia was reported in $83 \%$ (10/12 patients), mainly initially. Additional features included hypertonia/spasticity in $75 \%$ (6/8 patients) and stereotypic movements in $75 \%$ (6/8 patients). Ten patients displayed periods of intermittent irritability/extreme agitation, with crying, increased sweating, and involuntary movements. Sixty-seven percent (8/12 patients) were reported with no visual interaction, and 6 patients had nystagmus.

Eighty-six percent (19/22 patients) were reported with seizures. Of 11 patients with epilepsy, EEG data were available. Eighty percent were reported with seizure onset within the first 4 days of life (total range 1st hour of life to 5.5 months). Epilepsy syndrome classification remained difficult due to the high variability of seizure types, duration, frequency, and EEG abnormalities. Often, seizures were reported as frequent and/or long lasting with variable seizure types including focal, multifocal, generalized, and myoclonic seizures. Seven patients had recurrent status epilepticus, some of which lasted several hours. At epilepsy onset, EEG showed various patterns, such as focal, bilateral, multifocal epileptic discharges, hypsarrhythmia, and even a "focal migrating seizure-like" pattern (Table 1, e-1, links. lww.com/NXG/A195, and e-2, links.lww.com/NXG/A196). At follow-up, seizure semiology had not changed. Twenty-eight percent ( $5 / 18$ patients) were reported with seizures sensitive to fever or infections, with increased seizure frequency under those circumstances. Several antiepileptic drugs (AEDs) were tried; 2 patients responded partly to vigabatrin, and 1 had a positive response to ketogenic diet. Seventy-nine percent of the patients had pharmacoresistant epilepsy (15/19 patients). Of interest, $27 \%$ (6/22 patients) were reported with no seizures or were seizure free at follow-up. Patient 3 and patients 16, 17, and 18 had no epilepsy. Patient 4 only had seizures during a course of meningoencephalitis, and patient 21 was reported with febrile seizures only. ${ }^{11}$

Cranial MRI was performed in almost all patients $(21 / 22$ patients with data). Figure 1 displays characteristic neuroimaging features in the patients. Characteristic features include cortical atrophy $(89 \%, 16 / 18$ patients $)$ and cerebellar atrophy $(61 \%, 11 / 18$ patients), cortical structural anomalies (56\%, 10/18 patients) including simplified gyral pattern and pachygyria, hypoplasia of the corpus callosum (79\%, 15/19 patients), delayed myelination (88\%, 15/17 patients), ex vacuo enlargement of internal and external liquor spaces, and widening of subarachnoid spaces ( $95 \%, 18 / 19$ patients). No abnormalities of the brain stem were reported. Progressive atrophy is most evident in cranial imaging of patient 2 with almost 9-year timespan to follow-up. In this patient, progressive atrophy is evident in the supratentorial brain regions with reduced white matter bulk and pachygyria and of the corpus callosum, which is described as hypoplastic at age 14 weeks and completely atrophic at age 9 years. One reported patient (patients 21) ${ }^{11}$ was described with no structural defaults on MRI.

Additional features included hepatosplenomegaly or elevated liver enzymes in 2 patients and ventricular septum defect, hydronephrosis with unilateral hydroureter, and tracheomalacia as single reports. The patients showed mild facial dysmorphism, including long nose with upturned nose tip, 
Table 1 Genetic and clinical data of 10 new patients with biallelic variants in QARS

\begin{tabular}{lllll}
\hline Patient ID & 1 & 2 & 3 & 4 \\
\hline
\end{tabular}

\begin{tabular}{llllll}
\hline Family ID & 1 & 2 & 3 & 4 \\
\hline
\end{tabular}

Ethnicity

European Turkish

n.r.

$38+2$

38

$38+2$

$37+6$

39

$0.7 \mathrm{SD}$
$0.2 \mathrm{SD}$
$-0.9 \mathrm{SD}$

$-0.9$

$-0.9 \mathrm{SD} \quad-1.9 \mathrm{SD}$

$-1.9 \mathrm{SD}$

38

-0.4 SD

39

\begin{tabular}{ll}
\hline Weight & -2.3 \\
\hline Length & -1.9 \\
\hline OFC & -4.950 \\
\hline
\end{tabular}

$-3.6 \mathrm{SD}$

$\begin{array}{ll}1.1 \mathrm{SD} & -2 . \\ -2.5 \mathrm{SD} & \text { n.r. } \\ & \text { n.r. }\end{array}$

n.r.

$-3.5 \mathrm{SD}$
$-3.2 \mathrm{SD}$

$-1.9 \mathrm{SD}$
$-2.3 \mathrm{SD}$
$-3.4 \mathrm{SD}$

$-0.4 \mathrm{SD}$
$-0.2 \mathrm{SD}$
$-3.3 \mathrm{SD}$

\section{Measurements at}

follow-up

\begin{tabular}{|c|c|c|c|c|c|c|c|c|c|c|}
\hline Age at follow-up & - & $94 / 12 y$ & $106 / 12 y$ & $51 / 12 y$ & $46 / 12 y$ & $26 / 12 y$ & $26 / 12 y$ & $22 / 12 y$ & $5 \mathrm{mo}$ & $9 y$ \\
\hline Weight & - & $-0.8 \mathrm{SD}$ & $-0.6 \mathrm{SD}$ & $-4.3 \mathrm{SD}$ & Mean & $0.5 \mathrm{SD}$ & $1.7 \mathrm{SD}$ & $-3.2 \mathrm{SD}$ & $-0.8 \mathrm{SD}$ & $-4.4 \mathrm{SD}$ \\
\hline Length & - & $-2.8 \mathrm{SD}$ & $-1.3 \mathrm{SD}$ & $-4.2 \mathrm{SD}$ & $-2.2 \mathrm{SD}$ & $0.4 \mathrm{SD}$ & $0.3 \mathrm{SD}$ & $-4.3 \mathrm{SD}$ & $-0.7 \mathrm{SD}$ & $-3.5 \mathrm{SD}$ \\
\hline BMI & - & $0.9 \mathrm{SD}$ & $0.2 \mathrm{SD}$ & $-1.2 \mathrm{SD}$ & $1.7 \mathrm{SD}$ & $0.3 \mathrm{SD}$ & $2.0 \mathrm{SD}$ & $-0.2 \mathrm{SD}$ & $-0.5 \mathrm{SD}$ & $-2.1 \mathrm{SD}$ \\
\hline OFC & - & $-11.1 \mathrm{SD}$ & $-2.4 \mathrm{SD}$ & $-3.1 \mathrm{SD}$ & $-2.4 \mathrm{SD}$ & $-3.5 \mathrm{SD}$ & $-6.4 \mathrm{SD}$ & $-11.9 \mathrm{SD}$ & $-10.3 \mathrm{SD}$ & $-7.0 \mathrm{SD}$ \\
\hline
\end{tabular}

\section{Neurologic features}

\begin{tabular}{|c|c|c|c|c|c|c|c|c|c|c|}
\hline $\begin{array}{l}\text { Motor } \\
\text { development }\end{array}$ & Severe delay & Severe delay & Severe delay & Mild delay & Mild delay & Severe delay & Severe delay & Severe delay & Severe delay & Severe delay \\
\hline Sitting (at age) & No & No & No & n.r. & $10 \mathrm{mo}$ & $21 \mathrm{mo}$ & No & No & Too young & No \\
\hline Walking (at age) & No & No & No & $2 y$ & $42 / 12 y$ & No & No & No & Too young & No \\
\hline Hypotonia & n.r. & Initially hypotonia & n.r. & n.r. & No & n.r. & Severe & Initially hypotonia & Yes & No \\
\hline $\begin{array}{r}\text { Hypertonia/ } \\
\text { spasticity }\end{array}$ & n.r. & At 9 y spasticity & n.r. & n.r. & No & n.r. & At $2 \mathrm{y}$ contractures & $\begin{array}{l}\text { At } 2 \text { y severe } \\
\text { spasticity }\end{array}$ & No & Hypertonia \\
\hline $\begin{array}{l}\text { Speech } \\
\text { development }\end{array}$ & No speech & No speech & No speech & Speaks sentences & $\begin{array}{l}\text { Vocalizes, no } \\
\text { words }\end{array}$ & No speech & No speech & No speech & Too young & No speech \\
\hline $\begin{array}{c}\text { Stereotypies/ } \\
\text { involuntary } \\
\text { movements }\end{array}$ & n.r. & Yes & n.r. & n.r. & Yes & n.r. & Yes & No & No & $\begin{array}{l}\text { Dystonia } \\
\text { At } 3 y\end{array}$ \\
\hline $\begin{array}{l}\text { Episodes of } \\
\text { irritability }\end{array}$ & $\begin{array}{l}\text { Intermittent } \\
\text { irritability }\end{array}$ & $\begin{array}{l}\text { Intermittent } \\
\text { irritability }\end{array}$ & n.r. & n.r. & Rare & n.r. & $\begin{array}{l}\text { Intermittent } \\
\text { severe irritability }\end{array}$ & $\begin{array}{l}\text { Intermittent } \\
\text { severe } \\
\text { irritability }\end{array}$ & $\begin{array}{l}\text { Intermittent } \\
\text { irritability }\end{array}$ & No \\
\hline
\end{tabular}




\begin{tabular}{|c|c|c|c|c|c|c|c|c|c|c|}
\hline Visual interaction & n.r. & No & n.r. & n.r. & Yes & n.r. & No & No & No & No \\
\hline \multicolumn{11}{|l|}{ Epilepsy } \\
\hline Onset & $1 \mathrm{~h}$ after birth & $1 \mathrm{~h}$ after birth & No epilepsy & n.r. & $5.5 \mathrm{mo}$ & $2.5 \mathrm{mo}$ & $2 \mathrm{~h}$ after birth & $3 \mathrm{~h}$ after birth & $1 \mathrm{~h}$ after birth & 4th day of life \\
\hline Type & $\begin{array}{l}\text { Myoclonus, tonic- } \\
\text { clonic seizures }\end{array}$ & $\begin{array}{l}\text { Focal seizures with } \\
\text { generalization }\end{array}$ & - & $\begin{array}{l}\text { Encephalopathy } \\
\text { during } \\
\text { meningoencephalitis, } \\
\text { seizure free at follow- } \\
\text { up }\end{array}$ & $\begin{array}{l}\text { Focal seizures and } \\
\text { spasms }\end{array}$ & Tonic seizures & Myoclonic seizures & $\begin{array}{l}\text { Focal and } \\
\text { generalized } \\
\text { seizures }\end{array}$ & $\begin{array}{l}\text { Myoclonic } \\
\text { seizures, status } \\
\text { epilepticus }\end{array}$ & $\begin{array}{l}\text { Multifocal clonic } \\
\text { and tonic seizures }\end{array}$ \\
\hline $\begin{array}{l}\text { Effect of } \\
\text { antiepileptic } \\
\text { therapy }\end{array}$ & Pharmacoresistant & Pharmacoresistant & - & - & Pharmacoresistant & Pharmacoresistant & Pharmacoresistant & Pharmacoresistant & Pharmacoresistant & Pharmacoresistant \\
\hline \multicolumn{11}{|l|}{ cMRI } \\
\hline Age at cMRI & $18 / 12 y$ & $14 \mathrm{wk} / 94 / 12 \mathrm{y}$ & $10 y$ & n.r. & $6 \mathrm{mo} / 27 \mathrm{mo}$ & n.r. & $0 \mathrm{wk} / 5 \mathrm{wk}$ & $1 \mathrm{wk} / 19 \mathrm{wk}$ & $5 d$ & $18 \mathrm{mo} /+$ follow-up \\
\hline $\begin{array}{l}\text { Corpus callosum } \\
\text { anomalies }\end{array}$ & No & $\begin{array}{l}\text { At } 14 \text { wk } \\
\text { hypoplasia, } \\
\text { at } 9 \text { y complete } \\
\text { atrophy }\end{array}$ & Hypoplasia & Hypoplasia & No & Hypoplasia & Hypoplasia & Hypoplasia & No & Hypoplasia \\
\hline $\begin{array}{l}\text { Delayed } \\
\text { myelination }\end{array}$ & No & Hypomyelination & Hypomyelination & Hypomyelination & No & Hypomyelination & Too young & Hypomyelination & $\begin{array}{l}\text { No myelination } \\
\text { central } \\
\text { and subcortical }\end{array}$ & Hypomyelination \\
\hline $\begin{array}{l}\text { Cortical } \\
\text { anomalies }\end{array}$ & $\begin{array}{l}\text { White matter } \\
\text { atrophy, cortical } \\
\text { dysplasia }\end{array}$ & $\begin{array}{l}\text { Progressive } \\
\text { atrophy of } \\
\text { supratentorial } \\
\text { brain, } \\
\text { reduced white } \\
\text { matter, } \\
\text { pachygyria }\end{array}$ & $\begin{array}{l}\text { White matter } \\
\text { atrophy }\end{array}$ & n.r. & Moderate atrophy & $\begin{array}{l}\text { White matter } \\
\text { atrophy }\end{array}$ & $\begin{array}{l}\text { Progressive } \\
\text { atrophy of } \\
\text { supratentorial } \\
\text { brain, reduced } \\
\text { white matter, } \\
\text { pachygyria }\end{array}$ & $\begin{array}{l}\text { Mild atrophy of } \\
\text { cerebral } \\
\text { cortex, reduced } \\
\text { white } \\
\text { matter, pachygyria }\end{array}$ & $\begin{array}{l}\text { Symmetric cortical } \\
\text { pachygyria }\end{array}$ & $\begin{array}{l}\text { Progressive } \\
\text { atrophy } \\
\text { of the cerebral } \\
\text { cortex }\end{array}$ \\
\hline $\begin{array}{l}\text { Cerebellar } \\
\text { anomalies }\end{array}$ & $\begin{array}{l}\text { Atrophy of the } \\
\text { vermis cerebelli }\end{array}$ & $\begin{array}{l}\text { Mild atrophy of } \\
\text { cerebellum }\end{array}$ & Normal & n.r. & $\begin{array}{l}\text { Moderate atrophy } \\
\text { of the vermis } \\
\text { cerebelli }\end{array}$ & $\begin{array}{l}\text { Atrophy of the } \\
\text { vermis cerebelli }\end{array}$ & Normal & Normal & Normal & Normal \\
\hline Brain stem & Normal & Normal & Normal & n.r. & Normal & Normal & Normal & Normal & Normal & Normal \\
\hline $\begin{array}{l}\text { Enlarges cerebral } \\
\text { ventricles }\end{array}$ & Yes & Yes & Yes & n.r. & Yes & Yes & Yes & Yes & Yes & Yes \\
\hline
\end{tabular}



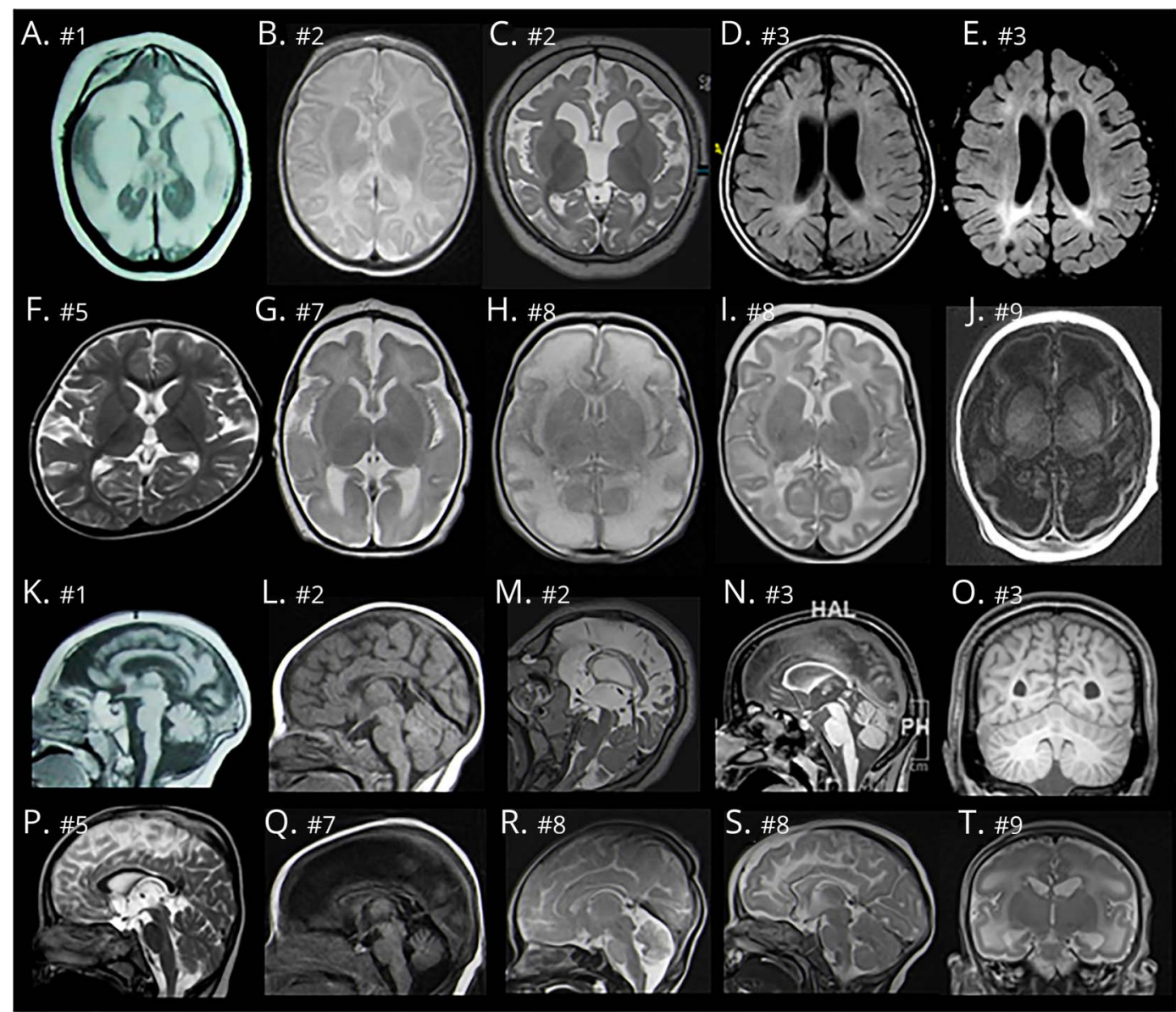

MRI data sets of the new patients 1 (1a,b), 2 (2a,c at 14 weeks; $2 b, d$ at $94 / 12$ years), 3 ( $3 a$ at 6 years; $3 b, c, d$ at 10 years), 5 (5a,b at 27 months), 7 (7a,b at 5 weeks), 8 ( $8 a, c$ at 1 week; 8b,d at 19 weeks), and 9 (9a,b). Cortical structural anomalies: axial magnetic resonance (MR) images show generalized atrophic supratentorial cerebral volume loss and enlargement of ventricles with progressive atrophy $(2$ and 8$)$, severe pachygyria $(1,2,7,8$, and 9$)$, and moderate pachygyria ( 3 and 5). Trim and flair sequences in patient $3(3 a, b)$ demonstrate progressive cerebral demyelination. Corpus callosum: sagittal MR images show a spectrum of anomalies of the corpus callosum with relative thinning $(3,6,7$, and 8$)$ and complete atrophy $(2,2 \mathrm{~d}$ at follow-up).

but overall no recognizable dysmorphic facial phenotype (figure 2).

\section{QARS genotype}

Patients in this cohort were either compound heterozygous (17/22) or homozygous (5/22 patients) for QARS variants. Most variants located in the N-terminal domain (NTD) and the catalytic domain (CATD), and only 2 variants located in the anticodon-binding domain (ABD). Three variants were recurrent: the variant p.(Gly45Val) was detected in patient 5 and siblings $13 / 14$, the variant p.(Tyr57His) was seen in 2 pairs of siblings $(11 / 12,19 / 20)$, and the splice variant c.2084+2 $2084+3$ del was seen in patients 6 and 22 . Two hot spots were found at position 57 (p.(Tyr57*), p.(Tyr57Cys), p.(Tyr57His)) and at position 378 (p.(Arg378Cys), p.(Arg378His)). All other variants were single reports (figure 3 ).

In silico models of the effects of the variants at the protein level were performed (figure e-1, links.lww.com/NXG/A198). In patient 1, p.(Arg67Trp), a surface variant, may interrupt so far unknown interactions, for instance with protein ligands. The crystal structure of this variant is unknown. The variant $p$. (Gln461 Argfs* 43 ) truncates QARS, and thus, the protein lacks part of the CATD and the entire ABD, making tRNA binding impossible. For patient 2 , the variant p.(Arg378Cys) is involved in stabilizing the fold of the loop in the connecting peptide 1 (CP1) domain, which is involved in interaction with tRNA. This amino acid replacement of arginine to cysteine likely causes minor folding or interaction defects in the CP1 domain. In the variant p. $\left(\operatorname{Arg} 523^{*}\right)$, the $\mathrm{ABD}$ is missing, which affects tRNA binding. In patient 3 , the same p.(Arg378His) change observed as in patient 2 was detected in homozygous state, causing minor folding or interaction defects in the CP1 domain. For patient 4 , the variant $p$. (Glu459Asnfs* 45$)$ truncates QARS, causing it to lack part of CATD and the entire ABD, and tRNA binding is abolished, resulting in a clear loss of function. The p.(Tyr435Cys) variant is involved in a number of hydrophobic interactions and hydrogen bonds stabilizing the fold of the surface loop at the border between CP1 domain and CATD, which are involved in interaction with tRNA. Replacement of 
tyrosine by cysteine likely affects folding and hence tRNA binding. In patient 5, p.(Gly45Val) is a surface variant that may interrupt other, yet unknown, interactions, for instance with protein ligands. The NTD fold might be locally affected. ${ }^{22}$ In patient 6 , the variant $\mathrm{p}$.(Arg265Cys) is located in the interface between NTD, CATD and the Hinge domain. Local structural rearrangement may be the consequence of this variant. For patient 7, the p.(Gly14Ser) variant is unlikely to affect folding or tRNA interaction; however, as it is a surface variant, it may interrupt other still unknown interactions, possibly with protein ligands, as is the case with p.(Gly45Val). The variant p.(Arg525Trp) might result in a changed orientation of ABD and thus affect tRNA binding. For patient 8 , the variant p.(Arg524Trp) is expected to lead to full protein expression, but misfolding and changed orientation of $\mathrm{ABD}$ may affect tRNA binding. The variant p.(Arg690Cys) may affect the local folding of human GlnRS. However, how this influences tRNA binding is unknown. In patient 9, variant p. (Tyr5 $\left.57^{*}\right)$ is located in the N-terminal part of the NTD, which causes only the first third of the domain to be expressed and a large C-terminal portion missing. No functional protein is expressed. Regarding the variant p.(Tyr57Cys), it is unlikely for a single amino acid variation to cause drastic conformational changes, but according to Ognjenović et al., ${ }^{22}$ variants in the NTD affect tRNA positioning and binding and decrease catalytic activity and stability of human GlnRS. These mutants will be unable to form a productive complex with tRNAGln. In patient 10, the variant p.(Arg403Trp) is located in the CP1 domain. The hydrophilic side chain of arginine is involved in a number of hydrogen bonds with the surrounding residues, stabilizing the fold of the CP1 domain. Its replacement by the larger aromatic tryptophan will cause local disturbance of interactions and likely misfolding. This might affect interaction with potential protein ligands. The surface variant p.(Ala2Thr) in the NTD is unlikely to affect fold or tRNA interaction but may interrupt other, yet unknown, interactions.

We also modeled previously published variants. In siblings 11 and $12,{ }^{1}$ the variant p.(Tyr57His) was described for patient 9 . The variant $\mathrm{p}$.(Arg515Trp) is expected to lead to full protein expression, but folding defects and changed orientation of ABD may affect tRNA binding. In patients 16,17 , and $18,{ }^{14}$ the homozygous p.(Val476Ile) variant, located in the CATD, may cause local disturbance of interactions and minor misfolding. In addition, the p.(Gly353Val) variant in patient 21 is likely to cause minor effects on folding, which might affect protein-protein interaction. This variant is located in the solvent exposed loop of the CP1 domain.

\section{Discussion}

In this work, we expand the known population of 12 individuals with biallelic pathogenic variants in QARS by 10 new patients and further delineate the QARS-associated clinical spectrum. Although most patients show a homogeneous phenotype, some patients (mainly the patients with a homozygous variant) display a milder presentation with better outcome.

Microcephaly was present in utero, at birth, or became evident during the early infantile period in all patients, being extremely severe with up to $-17 \mathrm{SD}$ and progressive. It seems that progression is worst in early infancy. Patients below or around 2 years of age have progression of their microcephaly with 4 to $7 \mathrm{SD}$ per year. Older patients have a moderate progression, albeit severe, around 2 to 4 SD per year. Part of this, or all, will probably be due to the fact that the normal brain grows the most during early childhood. In addition to microcephaly, some dysmorphic facial features can be present, including a long nose with upturned nose tip and dystopia canthorum. Developmental delay is evident in all patients, with severe delay in the patients with compound heterozygous variants (except patients 4 and 5) and mild to moderate delay in those with homozygous variants who also display mild progression in their speech and motor development, with some even learning to walk (patient 16 at age 10 years). Neurologically, hypotonia is a common feature, not only in the neonatal period but also in childhood. Furthermore, feeding difficulties seem to be a common problem, with several patients requiring gastroenteral tube feeding. Of interest periods of irritability or agitation with autonomic features were reported in several patients. The background for these episodes is not clarified, and might be

Figure 2 Photographs of patients 2, 7, 9, and 10

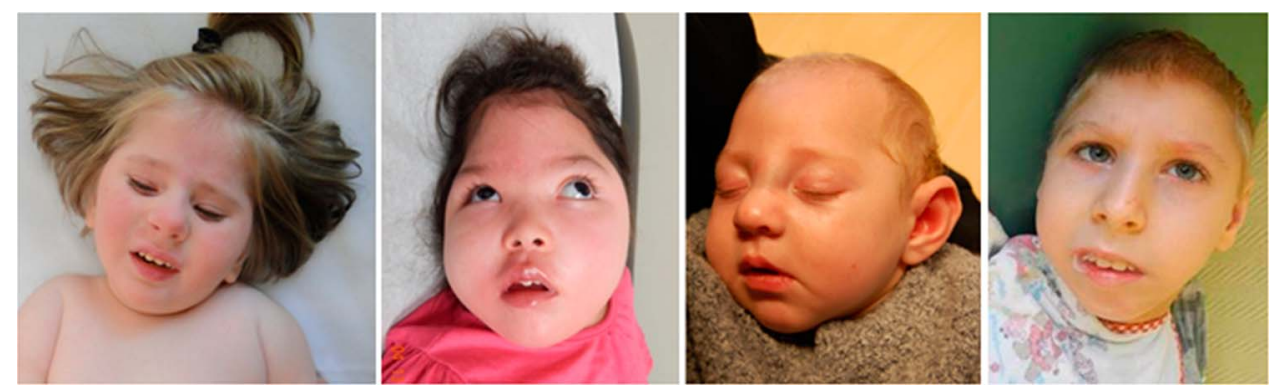

Patients 2, 7, 9, and 10 show mild facial dysmorphism, including narrow foreheads, as would be expected in children with microcephaly, sparse eyebrows, long nose with upturned tip of the nose, dystopia canthorum, dysconjugate gaze, full cheeks, and downturned corners of the mouth. 


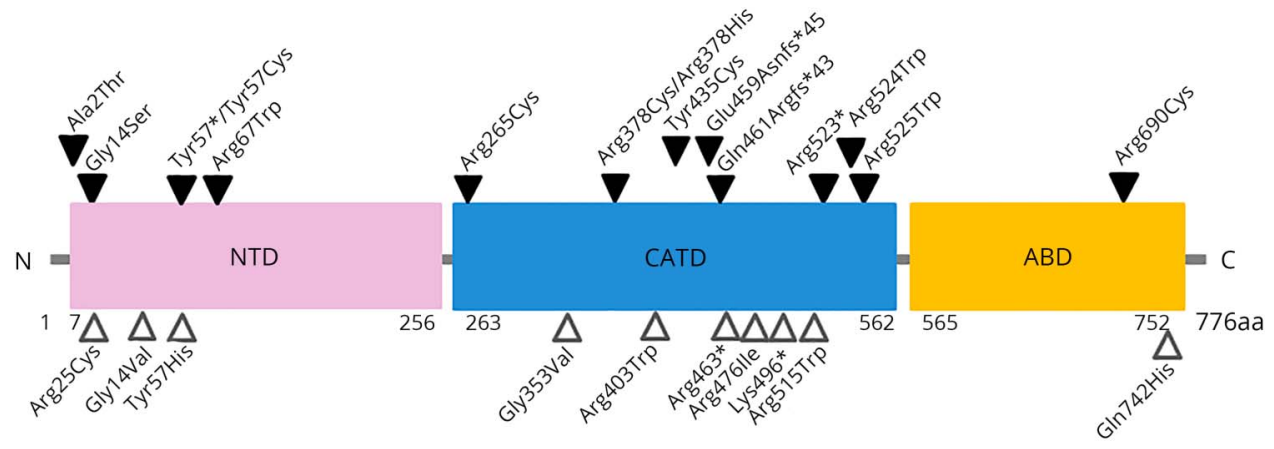

Observed QARS variants in a schematic illustration; NTD involved in RNA binding, CATD, and ABD. Novel variants (full arrows), published variants (empty arrows, gray). New and published QARS variants are listed in table e-3 (links.lww.com/NXG/A197). Protein Ref Seq NP_005042.1. ABD = anticodon-binding domain; CATD = catalytic domain; NTD = N-terminal domain.

underestimated, because those who displayed them were in their early childhood, and the mean age of this cohort is still fairly low. Agitation is a cluster of behaviors that can be found in a number of psychiatric disorders ${ }^{24}$ and have overlap with hyperactivity and restlessness. The agitation described in the patients of this cohort could be classified as aggressive physical and verbal. The underlying mechanisms of agitation are not yet clarified, but it is suggested that agitation runs through the same neurologic systems as movement disorders. This could be part of the explanation of why patients with pathogenic QARS variants experience these agitated episodes.

Epilepsy associated with deleterious variants in QARS is in most cases extremely severe. Most patients have seizure onset within the first few days and often within the first few hours of life. Focal seizures seem to be the predominant seizure type, often described as multifocal, and often, seizure frequency is extremely high. Patients, who experienced status epilepticus, often had very long status episodes lasting several hours. At follow-up, epilepsy remained relentless and uncontrolled despite of different combinations of AEDs. As of now, the mechanisms underlying an epilepsy so severe are unknown, but a crucial function of the glutaminyl-tRNA synthetase can be postulated, and the in silico modeling indicated that most of the variants will damage the protein folding and expression. Furthermore, follow-up times are very short, and thus, developmental evolution in adolescence and adulthood in affected patients is still unknown.

Our study shows that some patients with QARS deleterious variants had a milder phenotype compared with the overall cohort. Patient 3 is microcephalic ( -2.4 SD at $106 / 12$ years) and severely disabled but does not have epilepsy or experienced seizures. Patient 4 is microcephalic ( -3.1 SD at $51 / 12$ years), but shows only mild ID. He has gained the ability to walk and even speaks short sentences, albeit expressive language is delayed. Furthermore, he only experienced seizures as part of an episode of meningoencephalitis and has been seizure free since. Patient 5 is microcephalic ( -2.4 SD at $46 / 12$ years), but did not have seizure onset before age 5.5 months, and so far, the phenotype looks milder than expected with a seizure frequency of 1 seizure in 3 months at follow-up. He is currently classified with mild ID. Of interest, one of his variants only shows minor structural changes by in silico modeling, which may help explain the milder phenotype. Patient 21 is reported to be microcephalic (no measurements available) and has experienced febrile seizures only that resolved spontaneously. His MRIs were reported to be normal, and he was classified with mild ID. ${ }^{11}$ His homozygous variant showed only minor effects on folding when modeled, which could support the milder outcome. The variant is seen one time as heterozygous in gnomAD. Siblings 16 and 17, and patient 18, all Ashkenazi Jews, have mild to moderate ID and have not developed seizures at the last follow-up (at age 10 years, 7 6/12 years, and 3 years, respectively). ${ }^{14}$ It should be noted that the heterozygous form of the variant p.(Val476Ile) has a high incidence (allele count 443) in gnom $\mathrm{AD}$, and furthermore, one healthy homozygous carrier is listed, which might suggest that this variant could be a benign polymorphism. However, functional analyses in the original study ${ }^{14}$ showed a $67 \%$ decrease in QARS activity, and in silico modeling performed in this study supports a disease-causing function of the variant. Thus, we classified the variant as "likely pathogenic." ${ }^{18}$ One can speculate that ethnicity-based differences might attribute to the differential phenotypic expression as the homozygous carrier listed in gnomAD is of south Asian origin.

Of note, 5 of the above discussed 7 patients with a milder phenotype carry a homozygous pathogenic missense variant in QARS. Thus, it somehow seems that homozygosity is protective for the risk of developing epilepsy. This phenomenon has not been seen in the other bifunctional tRNA synthetase KARS. ${ }^{25}$ However, it could be speculated that harboring compound heterozygous variants is worse because it interferes with protein building in two different spots compared with homozygous variants that alter the protein in a milder and alike way. Why patients 4 and 5, with compound heterozygous variants, also display a less severe phenotype remains unknown. Another explanation might be that 
compound heterozygosity with one protein truncated (null allele) is more deleterious and that homozygous truncating variants in QARS are in fact lethal. Therefore, viable homozygous missense variants may be hypomorphic variants, which result in a milder phenotype compared with compound heterozygous variants with one null allele and another hypomorphic allele.

In most patients with pathogenic variants in QARS, the clinical picture is uniform and consists of the triad of primary or secondary progressive microcephaly, moderate or severe ID, and severe pharmacoresistant epilepsy. However, our cohort shows that the phenotype is broader than expected with milder phenotypes in some patients. Nonetheless, the presence of the core triad-microcephaly, developmental disability, and early-onset refractory epilepsy-in a young child should elicit a search for biallelic variants in QARS, either using a gene panel, because this triad is also common in other epilepsies, or when evaluating exome data. Longer follow-up and the addition of more patients to this exclusive cohort are necessary to gain a better understanding of QARS functioning and the associated phenotype.

\section{Acknowledgment}

This study would not have been possible without the invaluable assistance of the patients and their families. The authors specially thank Francesco Brancati for editing the manuscript. The authors acknowledge Genome.One for providing the whole-genome sequencing.

\section{Study funding}

G. Mirzaa is funded by the NINDS by award K08NS092898 and Jordan's Guardian Angels, United States. G. Baynam and C. Poulton received funding from Undiagnosed Diseases Program, Genetic Services of Western Australia, acknowledging funding from the Angela Wright Bennett Foundation and the McCusker Charitable Foundation. F. Brancati was funded by the Undiagnosed Disease Network - Italy (UDNItaly) PGR00229-PGR00919 and Farmindustria, acknowledging founding members Domenica Taruscio and Marco Salvatore from Istituto Superiore di Sanità, Roma, Italy. The content is solely the responsibility of the authors and does not necessarily represent the official views of the NIH. The funding sources had no role in the design and conduct of the study, collection, management, analysis and interpretation of the data, preparation, review, or approval of the manuscript, or decision to submit the manuscript for publication.

\section{Disclosure}

All authors report no disclosures. Go to Neurology.org/NG for full disclosure.

\section{Publication history}

Received by Neurology: Genetics May 1, 2019. Accepted in final form September 25, 2019.

\section{References}

1. Zhang X, Ling J, Barcia G, et al. Mutations in QARS, encoding glutaminyl-tRNA synthetase, cause progressive microcephaly, cerebral-cerebellar atrophy, and intractable seizures. Am J Hum Genet 2014;94:547-558.

2. Kodera $\mathrm{H}$, Osaka $\mathrm{H}$, Iai $\mathrm{M}$, et al. Mutations in the glutaminyl-tRNA synthetase gene cause early-onset epileptic encephalopathy. J Hum Genet 2015;60:97-101.

3. Abbott JA, Francklyn CS, Robey-Bond SM. Transfer RNA and human disease. Front Genet 2014;5:158.

4. Friedman J, Smith DE, Issa MY, et al. Biallelic mutations in valyl-tRNA synthetase gene VARS are associated with a progressive neurodevelopmental epileptic encephalopathy. Nat Commun 2019;10:707.

5. Siekierska A, Stamberger H, Deconinck T, et al. Biallelic VARS variants cause developmental encephalopathy with microcephaly that is recapitulated in vars knockout zebrafish. Nat Commun 2019;10:708.

6. Konovalova S, Tyynismaa H. Mitochondrial aminoacyl-tRNA synthetases in human disease. Mol Genet Metab 2013;108:206-211.

7. Wolf NI, Salomons GS, Rodenburg RJ, et al. Mutations in RARS cause hypomyelination. Ann Neurol 2014;76:134-139.

8. Casey JP, McGettigan P, Lynam-Lennon N, et al. Identification of a mutation in LARS as a novel cause of infantile hepatopathy. Mol Genet Metab 2012;106:351-358.

9. Sofou K, Kollberg G, Holmström M, et al. Whole exome sequencing reveals mutations in NARS2 and PARS2, encoding the mitochondrial asparaginyl-tRNA synthetase and prolyl-tRNA synthetase, in patients with Alpers syndrome. Mol Genet Genomic Med 2015;3:59-68.

10. Simons C, Griffin LB, Helman G, et al. Loss-of-function alanyl-tRNA synthetase mutations cause an autosomal-recessive early-onset epileptic encephalopathy with persistent myelination defect. Am J Hum Genet 2015;96:675-681.

11. Alabdullatif MA, Al Dhaibani MA, Khassawneh MY, El-Hattab AW. Chromosomal microarray in a highly consanguineous population: diagnostic yield, utility of regions of homozygosity, and novel mutations. Clin Genet 2017;91:616-622.

12. Datta A, Ferguson A, Simonson C, et al. Case report. J Child Neurol 2017;32: 403-407.

13. Fuchs SA, Schene IF, Kok G, et al. Aminoacyl-tRNA synthetase deficiencies in search of common themes. Genet Med 2019;21:319-330.

14. Leshinsky-Silver E, Ling J, Wu J, et al. Severe growth deficiency, microcephaly, intellectual disability, and characteristic facial features are due to a homozygous QARS mutation. Neurogenetics 2017;18:141-146.

15. Salvarinova R, Ye CX, Rossi A, et al. Expansion of the QARS deficiency phenotype with report of a family with isolated supratentorial brain abnormalities. Neurogenetics 2015; 16:145-149.

16. Baynam G, Broley S, Bauskis A, et al. Initiating an undiagnosed diseases program in the Western Australian public health system. Orphanet J Rare Dis 2017;12:83.

17. Sobreira N, Schiettecatte F, Valle D, Hamosh A. GeneMatcher: a matching tool for connecting investigators with an interest in the same gene. Hum Mutat 2015;36: 928-930.

18. Scheffer IE, Berkovic S, Capovilla G, et al. ILAE classification of the epilepsies: position paper of the ILAE Commission for Classification and Terminology. Epilepsia 2017;58:512-521.

19. Fisher RS, Cross JH, French JA, et al. Operational classification of seizure types by the International League Against Epilepsy: position paper of the ILAE Commission for Classification and Terminology. Epilepsia 2017;58:522-530.

20. Richards S, Aziz N, Bale S, et al. Standards and guidelines for the interpretation of sequence variants: a joint consensus recommendation of the American College of Medical Genetics and Genomics and the Association for Molecular Pathology. Genet Med 2015;17:405-424.

21. Nykamp K, Anderson M, Powers M, et al. Sherloc: a comprehensive refinement of the ACMG-AMP variant classification criteria. Genet Med 2017;19:1105-1117.

22. Ognjenović J, Wu J, Matthies $\mathrm{D}$, et al. The crystal structure of human GlnRS provides basis for the development of neurological disorders. Nucleic Acids Res 2016;44: 3420-3431.

23. Emsley P, Lohkamp B, Scott WG, Cowtan K. Features and development of Coot. Acta Crystallogr D Biol Crystallogr 2010;66:486-501.

24. Lindenmayer JP. The pathophysiology of agitation. J Clin Psychiatry 2000;61(suppl 14):5-10.

25. McMillan HJ, Humphreys P, Smith A, et al. Congenital visual impairment and progressive microcephaly due to Lysyl-transfer ribonucleic acid (RNA) synthetase (KARS) mutations: the expanding phenotype of aminoacyl-transfer RNA synthetase mutations in human disease. J Child Neurol 2015;30:1037-1043. 


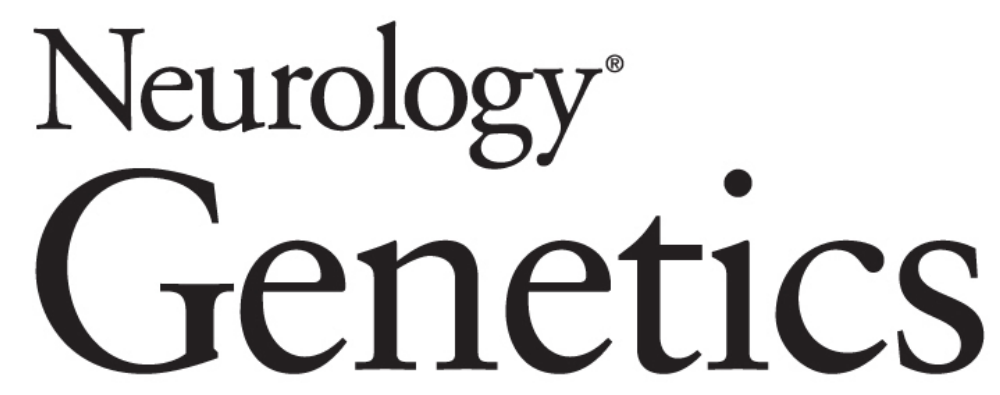

\section{Defining and expanding the phenotype of $Q A R S$-associated developmental epileptic encephalopathy}

Katrine M. Johannesen, Diana Mitter, Robert Janowski, et al.

Neurol Genet 2019;5;

DOI 10.1212/NXG.0000000000000373

\section{This information is current as of December 10, 2019}

\section{Updated Information \&} Services

References

Subspecialty Collections

Permissions \& Licensing

Reprints including high resolution figures, can be found at: http://ng.neurology.org/content/5/6/e373.full.html

This article cites 25 articles, 0 of which you can access for free at: http://ng.neurology.org/content/5/6/e373.full.html\#\#ref-list-1

This article, along with others on similar topics, appears in the following collection(s):

All Epilepsy/Seizures

http://ng.neurology.org//cgi/collection/all_epilepsy_seizures Association studies in genetics

http://ng.neurology.org//cgi/collection/association_studies_in_genetics Mental retardation

http://ng.neurology.org//cgi/collection/mental_retardation

MRI

http://ng.neurology.org//cgi/collection/mri

Information about reproducing this article in parts (figures,tables) or in its entirety can be found online at:

http://ng.neurology.org/misc/about.xhtml\#permissions

Information about ordering reprints can be found online: http://ng.neurology.org/misc/addir.xhtml\#reprintsus

Neurol Genet is an official journal of the American Academy of Neurology. Published since April 2015, it is an open-access, online-only, continuous publication journal. Copyright Copyright (C) 2019 The Author(s). Published by Wolters Kluwer Health, Inc. on behalf of the American Academy of Neurology.. All rights reserved. Online ISSN: 2376-7839.

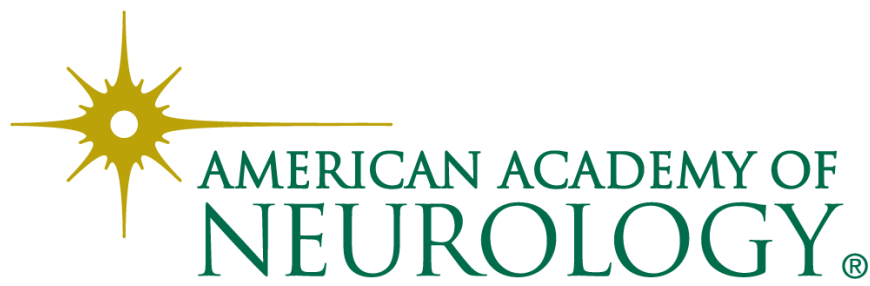

